\title{
Salvianolic Acid B Ameliorates Hyperglycemia and Dyslipidemia in $d b / d b$ Mice through the AMPK Pathway
}

\author{
Ming-Qing Huang ${ }^{\mathrm{a}, \mathrm{b}}$ Cai-Jie Zhou ${ }^{\mathrm{b}, c} \quad$ Yi-Ping Zhang ${ }^{\mathrm{d}} \quad$ Xiao-Qin Zhang ${ }^{\mathrm{a}}$ Wen $\mathrm{Xu}^{\mathrm{a}}$ \\ Jing Lin ${ }^{a}$ Pei-Jian Wang
}

${ }^{a}$ College of Pharmacy, Fujian University of Traditional Chinese Medicine, Fuzhou, Fujian, 'bShenzhen Key Laboratory of ENT, Institute of ENT \& Longgang ENT hospital, 'Beijing University of Chinese Medicine Shenzhen Hospital, Shenzhen, 'Third Institute of Oceanography, State Oceanic Administration, Xiamen, eDepartment of Cardiology, the First Affiliated Hospital, Chengdu Medical College, Chengdu, Sichuan,

China

\section{Key Words}

Salvianolic acid B • AMPK • GLUT4 • PPAR $\alpha$ Type 2 Diabetes

\begin{abstract}
Background/Aims: Salvianolic acid B (Sal B), a major polyphenolic compound of Salvia miltiorrhiza Bunge, has been shown to possess potential antidiabetic activities. However, the action mechanism of SalB in type 2 diabetes has not been investigated extensively. The present study was designed to investigate the effects of Sal B on diabetes-related metabolic changes in a spontaneous model of type 2 diabetes, as well as its potential molecular mechanism. Methods: Male C57BL/KsJ-db/db mice were orally treated with Sal B (50 and $100 \mathrm{mg} / \mathrm{kg}$ ) or metformin (positive drug, $300 \mathrm{mg} / \mathrm{kg}$ ) for 6 weeks. Results: Both doses of Sal B significantly decreased fasting blood glucose, serum insulin, triglyceride and free fatty acid levels, reduced hepatic gluconeogenic gene expression and improved insulin intolerance in $d b / d b$ mice. High dose Sal B also significantly improved glucose intolerance, increased hepatic glycolytic gene expression and muscle glycogen content, and ameliorated histopathological alterations of pancreas, similar to metformin. Sal B treatment resulted in increased phosphorylated AMPactivated protein kinase (p-AMPK) protein expression in skeletal muscle and liver, increased glucose transporter 4 (GLUT4) and glycogen synthase protein expressions in skeletal muscle, and increased peroxisome proliferator-activated receptor alpha (PPAR $\alpha$ ) and phosphorylated acetyl CoA carboxylase ( $p$-ACC) protein expressions in liver. Conclusion: Our data suggest that Sal B displays beneficial effects in the prevention and treatment of type 2 diabetes at least in part via modulation of the AMPK pathway.




\section{Cellular Physiology Cell Physiol Biochem 2016;40:933-943 \begin{tabular}{ll|l} 
and Biochemistry Published online: December 07, 2016 & $\begin{array}{l}\text { (c) } 2016 \text { The Author(s). Published by S. Karger AG, Basel } \\
\text { www.karger.com/cpb }\end{array}$ \\
\hline
\end{tabular} \\ Huang et al.: Salvianolic Acid B Ameliorates Hyperglycemia and Dyslipidemia}

\section{Introduction}

Type 2 diabetes is a metabolic disorder characterized by carbohydrate, protein, and fat metabolism due to insulin resistance and is the most prevalent form of diabetes [1, 2 ]. In the past few decades, the prevalence of type 2 diabetes has considerably increased worldwide and in China and is expected to increase further in the future because of poor diet and lack of exercise [3, 4]. Currently many kinds of oral antidiabetic drugs have been used in the treatment of type 2 diabetes, such as sulphonylureas, thiazolidinediones, biguanides, $\alpha$-glycosidase inhibitors, and dipeptidyl peptidase-IV inhibitors. However, these medications also have considerable adverse effects and high rates of secondary failure $[1,5]$. Therefore, there has been a growing interest in the therapeutic use of natural products for type 2 diabetes recently, especially those derived from herbs. This is mainly because natural products are usually considered less toxic with fewer side effects than synthetic drugs [6, 7].

Salvianolic acid B (Sal B) is the most abundant and bioactive member of polyphenolic compounds in Salvia miltiorrhiza, which has been widely used in clinic for the treatment of a variety of human diseases [8-13]. Although its most common use is in the treatment of cardio-cerebral vascular diseases [14-16], Sal B is recently reported to possess a number of potential implications in the treatment of insulin resistance, obesity, and type 2 diabetes [17-20]. Sal B or Salvia miltiorrhiza extract improved glycemic control, dyslipidemia, and insulin sensitivity in high fat diet and streptozocin-induced type 2 diabetic rats $[17,19]$. Furthermore, Sal B can moderate lipids and reduce obesity in high-fat diet-induced obese C57BL/6J mice by suppressing peroxisome proliferator-activated receptor gamma (PPAR $\gamma$ )mediated adipogenesis [18]. However, despite evidence of the beneficial effects of Sal B, the clear molecular mechanism remain a mystery, especially in modulating glucose metabolism.

To our knowledge, no study has assessed Sal B effects on C57BL/KsJ- $d b / d b$ mice, an spontaneous animal model similar to human type 2 diabetes [21]. In this model, diabetesrelated metabolic changes including hyperglycemia, hyperinsulinemia, glucose intolerance, and insulin resistance can be maintained $[22,23]$. Therefore, $d b / d b$ mice provide a suitable model to investigate the effects of Sal B on metabolic changes and molecular targets in type 2 diabetes. Moreover, AMP-activated protein kinase (AMPK) is an important cellular energy sensor, and active AMPK orchestrates a variety of metabolic processes, most of which lead to reduced energy storage and increased energy production [24, 25]. Several major insulinsensitizing agents such as metformin and rosiglitazone are thought to have beneficial effects mainly by activating AMPK [26]. Natural products including berberine, curcumin and resveratrol are also reported to have potential antidiabetic properties, at least in part, by modulating the AMPK pathway $[23,27,28]$. These studies emphasize the potential utility of targeting the AMPK pathway in the treatment of type 2 diabetes.

Herein, the present study is aimed to study the effects of Sal B treatment on glucose and lipid metabolic changes in spontaneous type 2 diabetic $d b / d b$ mice, compared to the positive drug metformin. Then, we further investigated whether the AMPK pathway in skeletal muscle and liver are related to the effects of Sal B treatment in this model.

\section{Materials and Methods}

Animals

Forty male C57BL/KsJ- $d b / d b$ mice (5 weeks of age) were procured from Model Animal Research Center of Nanjing University (Nanjing, China). All animals were examined for clinical signs of ill health upon receipt and observed within 1 week of arrival. They were housed under controlled conditions (temperature, $23 \pm 2{ }^{\circ} \mathrm{C}$; relative humidity, $40-60 \% ; 12 \mathrm{~h}$ light/ dark cycle) and allowed free access to water and food. The mice were fed with a commercial pellet diet obtained from the Center of Laboratory Animal Science of Guangdong Province (Foshan, China). The experimental protocols for this study were approved by the Institutional Animal Care and Use Committee and the animals were kept according to the institutional ethical guideline of Fujian University of Traditional Chinese Medicine.

\section{KARGER}




\section{Cellular Physiology Cell Physiol Biochem 2016;40:933-943

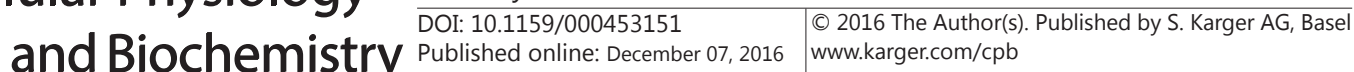 \\ Huang et al.: Salvianolic Acid B Ameliorates Hyperglycemia and Dyslipidemia}

Drugs and reagents

SalB (Fig. 1) was obtained from Shanghai Tauto

Biotech Co., (Shanghai, China), and its purity was more than $98 \%$ analyzed by high-performance liquid chromatography. Metformin was purchased from Sino-American Shanghai Squibb Pharmaceutical Co., Ltd (Shanghai, China). Assay kits of total cholesterol (TC), triglyceride (TG), free fatty acid (FFA), and glycogen were obtained from Nanjing Jiancheng Bio-Engineering Research Institute (Nanjing, China). Radioimmunoassay kit of insulin was obtained from Linco Research Co., Ltd (MA, USA). Antibodies of glucose transporter 4 (GLUT4), peroxisome proliferator-activated receptor alpha (PPAR $\alpha$ ), and phosphorylated acetyl CoA carboxylase (p-ACC) were purchased from Santa Cruz Biotechnology, Inc. (Santa Cruz, CA, USA). Antibodies of AMP-activated protein kinase (AMPK), phosphorylated AMPK (p-AMPK) and glycogen synthase were purchased from Cell Signaling Technology, Inc. (Beverly, MA, USA). All other chemicals were of the highest grade available.

\section{Animal grouping and treatment}

The $d b / d b$ mice ( 6 weeks of age) were randomly divided into four groups $(\mathrm{n}=10)$, namely, control group, low-dose Sal B treated group, high-dose Sal B treated group, and metformin treated group. Control $d b / d b$ mice were orally administered with saline, while low-dose and high-dose Sal B-treated mice were orally administered with Sal B 50 and $100 \mathrm{mg} / \mathrm{kg}$ daily, and metformin-treated mice was administrated with metformin $300 \mathrm{mg} / \mathrm{kg}$ daily for 6 weeks. The doses of Sal B were determined based on our previous study [18]. The body weight were measured every 2 weeks during the experimental period. At the end of the experiment, all animal were anesthetized with ether after fasting for $12 \mathrm{~h}$. Whole blood was collected and serum was isolated for biochemical analysis. The liver and skeletal muscle were then removed, rinsed, immediately frozen in liquid nitrogen, and stored at $-80^{\circ} \mathrm{C}$ until analysis.

\section{Glucose tolerance test and insulin tolerance test}

Intraperitoneal glucose tolerance test (IPGTT) was performed after an overnight fast (12 h). The mice were injected intraperitoneally with glucose $(0.5 \mathrm{~g} / \mathrm{kg})$, and the blood glucose levels in tail blood were determined at $0,30,60$, and $120 \mathrm{~min}$ after glucose administration. Intraperitoneal insulin tolerance test (IPITT) was performed on a different day. Humulin R $(0.75 \mathrm{U} / \mathrm{kg}$ ) (Eli Lilly and Co., IN, USA) in sterile saline was administered via injection into the peritoneal cavity. Glucose levels in tail blood were determined at 0 , 15,30 , and $60 \mathrm{~min}$ after insulin injection [18].

Measurement of blood glucose, serum lipids, and insulin

The fasting blood glucose level was measured using the venous blood from the tail vein using a glucometer (Roche, Mannheim, Germany) after fasting $12 \mathrm{~h}$. At the end of the experiment, whole blood was collected and serum was isolated for biochemical analysis. Serum levels of TC and TG were measured with a fully automated biochemical analyzer (ECHO, Rome, Italy). Serum FFA was measured using a UV-Vis 752 spectrophotometer (Lengguang Optical Instrument, Shanghai, China). Serum insulin level was determined by the SN-6100 $\gamma$-radiation-immunity counter (Beijing Chemclin Biotech, Beijing, China).

\section{Measurement of glycogen content in muscle}

The muscle glycogen concentration was determined as described previously [19, 29]. On the day of analysis, the frozen sample was thawed at room temperature and used for glycogen extraction. Each frozen tissue (about $50 \mathrm{mg}$ ) was extracted by $\mathrm{KOH}$ solution, precipitated with ethanol and redissolved in distilled water. Thereafter, the content of muscle glycogen was determined by spectrophotometer at $620 \mathrm{~nm}$ with commercial kit.

\section{Real-time quantitative PCR analysis}

The frozen liver was thawed and homogenized in Trizol reagent, and total RNA was extracted using the RNeasy mini kit (Qiagen, Germany). For real-time PCR, first-strand complementary DNA (cDNA) 


\section{Cellular Physiology Cell Physiol Biochem 2016;40:933-943 \begin{tabular}{l|l|l} 
and Biochemistry & DOI: 10.1159/000453151 & $\begin{array}{l}\text { C } 2016 \text { The Author(s). Published by S. Karger AG, Basel } \\
\text { www.karger.com/cpb }\end{array}$
\end{tabular} \\ Huang et al.: Salvianolic Acid B Ameliorates Hyperglycemia and Dyslipidemia}

was synthesized from total RNA in the Superscript First-Stand Synthesis System in accordance with the manufacturer's instructions (Life Technologies, NY, USA). cDNAs were quantified by PCR using SYBR Green real-time PCR master mix (Life Technologies, NY, USA) according the manufacturer's instructions. Primers were designed to determine pyruvate kinase (PK), glucokinase (GK), glucose-6-phosphatase (G6Pase) and phosphoenolpyruvate carboxykinase (PEPCK) upon request. Glyceraldehyde-3-phosphate dehydrogenase (GAPDH) was used as an internal control. Results were expressed as fold change relative to control group, after normalization to GAPDH.

\section{Western blot analysis}

The frozen liver and skeletal muscle were thawed and homogenized in ice-cold lysis buffer with a motor-driven Teflon pestle. The membrane fraction of muscle was prepared by differential centrifugation as described previously [30]. The protein concentrations were determined using the Bradford method. Immunoblotting for AMPK, p-AMPK, GLUT4, glycogen synthase, PPAR $\alpha$, and p-ACC were performed as described previously [31]. The equivalent of 30-50 $\mu \mathrm{g}$ of total protein was subjected to electrophoresis on a 10\% SDS-polyacrylamide gel, and the gel was transferred to a nitrocellulose membrane. The membrane was blocked in 5\% nonfat dry milk in TBST for $1 \mathrm{~h}$. The primary antibodies were used at a 1:1000-2000 dilution. The membrane was incubated with the primary antibodies for $16 \mathrm{~h}$ at $4{ }^{\circ} \mathrm{C}$. After the membranes were washed in PBS and $0.01 \%$ Tween-20, the respective secondary antibodies conjugated to horseradish peroxidase were applied for $2 \mathrm{~h}$. Immunoreactive signals were detected by enhanced chemiluminescence and quantified using a Gel Doc 2000 Imager (Bio-Rad, California, USA).

\section{Histopathology}

The pancreas was fixed in 4\% paraformaldehyde solution, embedded in paraffin and sectioned at 5 $\mu \mathrm{m}$. Sections were cut and mounted on glass slides. Paraffin was removed with xylene and alcohol. The sections were then stained with hematoxylin and eosin (HE). After dehydration by alcohol, each image of sections was examined under light microscope (Nikon, Tokyo, Japan).

\section{Statistical analysis}

The parameter values were expressed as the mean \pm standard error of the mean (SEM). The statistical analysis was performed using SPSS 16.0 software (SPSS Inc., Chicago, USA). The values were analyzed by one-way analysis of variance (ANOVA) followed by post-hoc Duncan's multiple range tests. Results were considered statistically significant at $p<0.05$.

\section{Results}

Effect of SalB on body weight

As shown in Fig. 2A, there was no significant intragroup variation in the basal body weight of $d b / d b$ mice. The body weights of $d b / d b$ mice in control group dramatically increased until the end of this experiment. Compared with the control group, the body weight were significantly decreased after high dose Sal B or metformin $(300 \mathrm{mg} / \mathrm{kg}$, as a positive drug) treatment from week 2 , and low dose Sal B also remarkably decreased body weight from week 4.

\section{Effect of SalB on hyperglycemia and glucose intolerance}

We next investigated the effects of Sal B on hyperglycemia and glucose intolerance in $d b / d b$ mice. Positive drug significantly inhibited hyperglycemia in $d b / d b$ mice from week 2 until week 6. After four weeks of treatment, Sal B (50 and $100 \mathrm{mg} / \mathrm{kg}$ ) significantly lowered fasting blood glucose level compared to the control group (Fig. 2B). An IPGTT was performed to determine the effect of Sal B on glucose intolerance at the end of the experimental period. Sal B (100 mg/kg) as well as metformin effectively improved glucose intolerance in $d b / d b$ mice (Fig. 2C).

\section{Effect of Sal B on hyperinsulinemia and insulin intolerance}

The effects of Sal B on hyperinsulinemia and insulin intolerance in $d b / d b$ mice were further investigated in this study. Sal B (50 and $100 \mathrm{mg} / \mathrm{kg}$ ) and metformin administered KARGER 
Fig. 2. Effects of Sal B on body weight gain (A), fasting blood glucose (B), IPGTT (C), serum insulin (D), IPITT (E), and lipids levels $(\mathrm{F})$ in C $57 \mathrm{BL} / \mathrm{KsJ}-d b /$ $d b$ mice. IPGTT, intraperitoneal glucose tolerance test; IPITT, intraperitoneal insulin tolerance test; TC, total cholesterol; $\mathrm{TG}$, triglyceride; FFA, free fatty acid. Data are expressed as mean $\pm \operatorname{SEM}(\mathrm{n}=$ 5-10). abc Means not sharing common superscript letters are significantly different between groups at $p<0.05$.
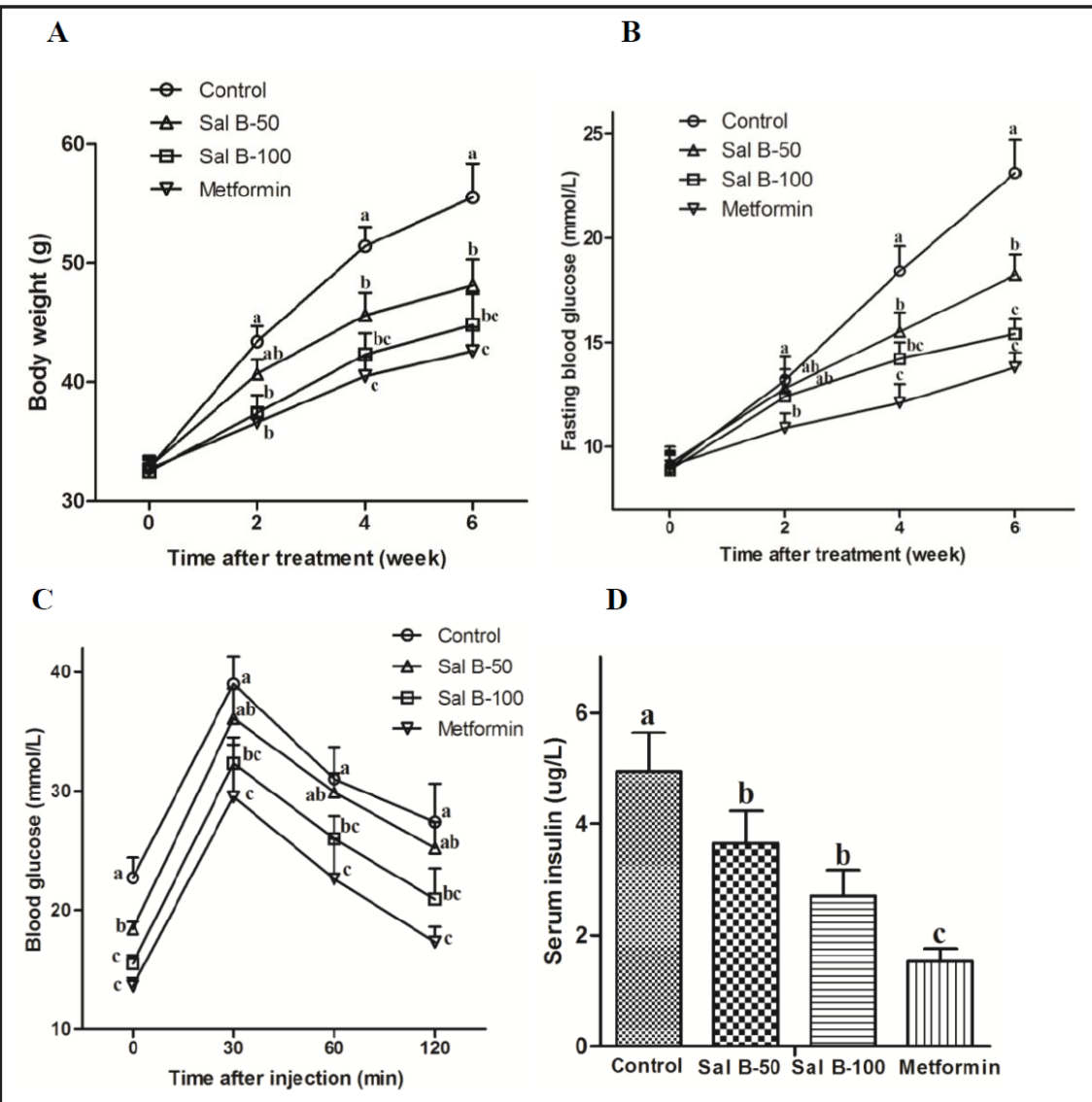

D
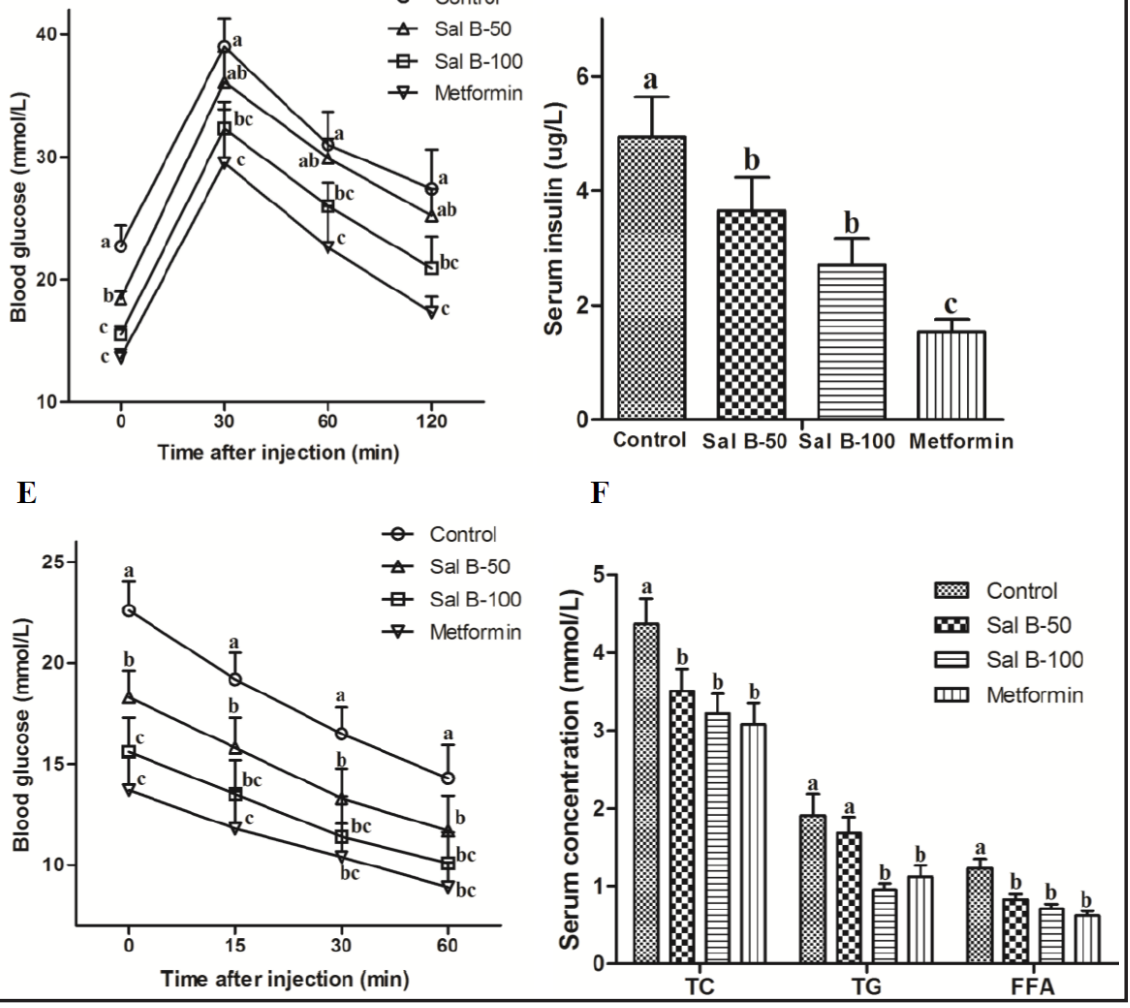

orally for 6 weeks significantly decreased the serum insulin levels compared to the control group (Fig. 2D). Moreover, both doses of Sal B as well as metformin also markedly improved insulin intolerance in $d b / d b$ mice (Fig. 2E).

\section{Effect of SalB on serum lipid profile}

Fig. $2 \mathrm{~F}$ depicts the values of serum TC, TG, and FFA in $d b / d b$ mice. After 6 weeks of drug treatment, serum levels of TC, TG, and FFA in high dose Sal B group were significantly lower than the control group. Low dose Sal B also tended to lower serum levels of TC and FFA. Similar to high dose Sal B, metformin significantly decreased serum levels of TC, TG, and FFA compared to the control group.

Effect of SalB on glycolytic and gluconeogenic enzyme genes expressions in liver

To study the effect of Sal B on glycolysis, we examined the mRNA expressions of PK and GK, two key glycolytic enzymes in liver. As shown in Fig. 3A, Sal B (100 mg/kg) as well 
as metformin significantly increased mRNA expressions of PK and GK in $d b / d b$ mice. Furthermore, high dose Sal B treated $d b / d b$ mice showed a significant decrease in the mRNA expressions of G6Pase and PEPCK, which are the two rate-limiting enzymes in the gluconeogenic process in liver. Similarly, low dose Sal B tended to lower PEPCK mRNA expression (Fig. 3B).

Effect of SalB on glycogen content, protein expressions of GLUT4 and glycogen synthase in skeletal muscle

The data for muscle glycogen changes was shown in Fig. 3C. Sal B (100 mg/kg) and metformin administered orally for 6 weeks significantly increased glycogen contents in skeletal muscle of diabetic mice (Fig. 3C). Moreover, GLUT4 protein expression in skeletal muscle was higher in diabetic mice treated with Sal B (50 and $100 \mathrm{mg} /$ $\mathrm{kg}$ ) or metformin compared to the control mice (Fig. 4A and B). In particular, they also markedly increased protein expression of glycogen synthase in skeletal muscle (Fig. 4A and C).

Effect of SalB on $p$-AMPK protein expression in liver and skeletal muscle, and PPAR $\alpha$ and $p$-ACC protein expressions in liver

As shown in Fig. 4 and 5, p-AMPK protein expression in skeletal muscle and liver were significantly increased in both doses of Sal $\mathrm{B}$ groups compared to the control group, however the total levels of AMPK in both tissues were not significantly changed by any treatment. Moreover, two doses of Sal B also significantly increased PPAR $\alpha$ and p-ACC protein expressions in liver compared to the control group. Similar promoting effects were also observed in metformin treated group.

\section{EffectofSalBonpancreaticmorphological changes in $\mathrm{db} / \mathrm{db}$ mice}

As shown in Fig. 6A, the pancreas of control mice exhibited obvious loss of islet boundary definition and vacuolar degeneration. In contrast, treatment with Sal B $(100 \mathrm{mg} / \mathrm{kg})$ or metformin markedly ameliorated these diabetes-induced histopathological alterations (Fig. 6C and D). But low dose Sal B did not show marked improvement compared to the control group (Fig. 6B).

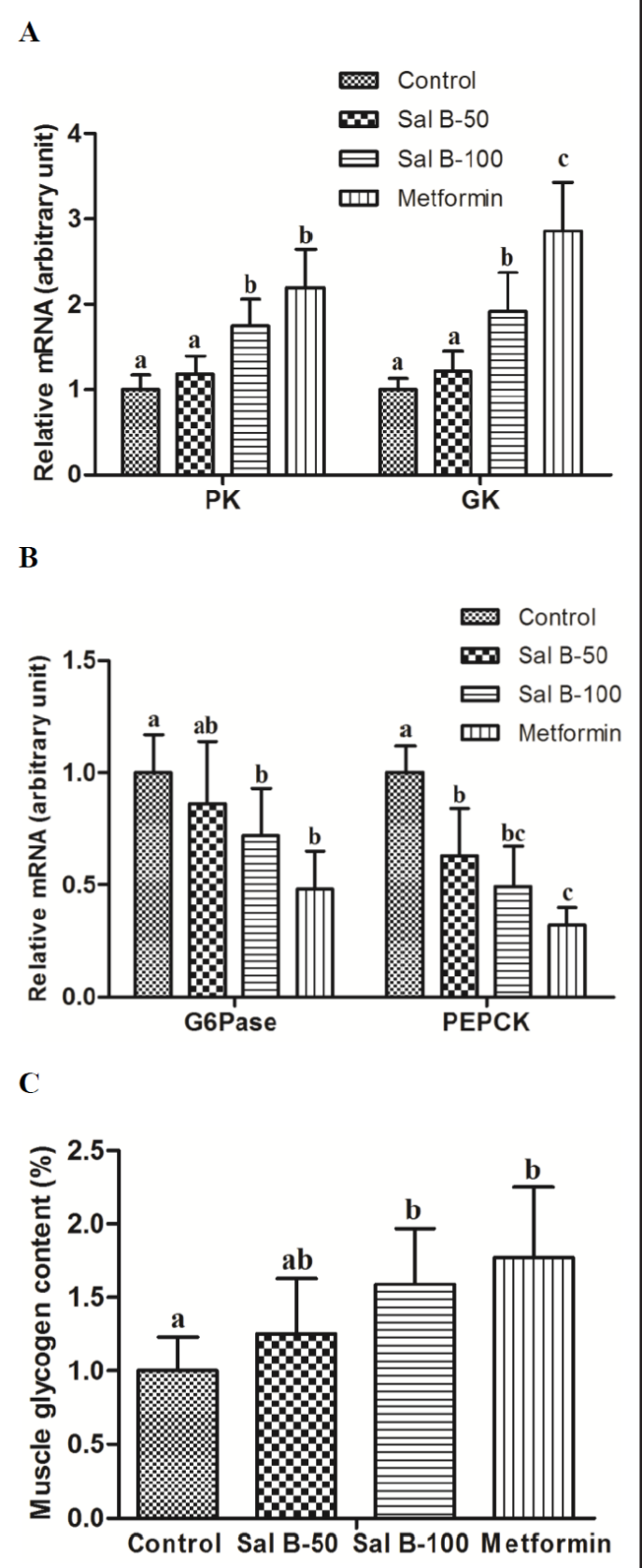

Fig. 3. Effects of Sal B on the hepatic glucose regulating enzyme mRNA exprestions (A-B) and muscle glycogen content (C) in C57BL/KsJ- $d b / d b$ mice. Data are expressed as mean \pm SEM $(n=5)$. ${ }^{\text {abc Means not }}$ sharing common superscript letters are significantly different between groups at $p<0.05$. 
Fig. 4. Effects of Sal B on GLUT4, glycogen synthase, p-AMPK, and AMPK protein expression in skeletal muscle of $\mathrm{C} 57 \mathrm{BL} / \mathrm{KsJ}-d b / d b$ mice. A: equal amounts of proteins were resolved on $10 \%$ SDS-PAGE and blotted with respective GLUT4, glycogen synthase, p-AMPK, and AMPK antibodies. B-E: the densitometric measurements of protein bands in A. Data are expressed as mean \pm

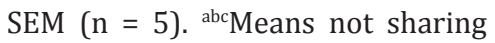
common superscript letters are significantly different between groups at $p<0.05$.

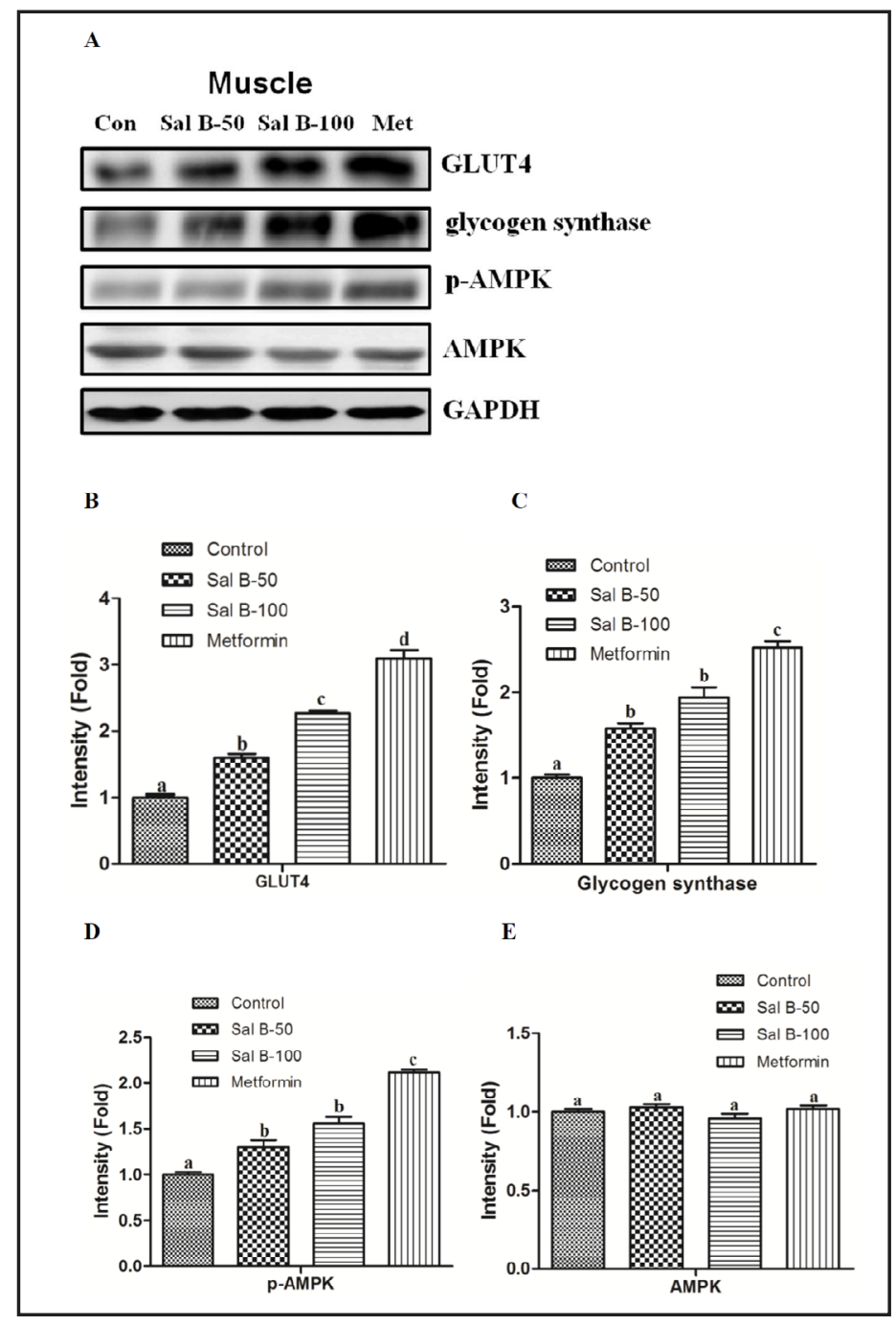

\section{Discussion}

More and more evidences indicate that Sal B exerts multiple beneficial effects on the metabolic syndrome and type 2 diabetes [17-20], although its extensive action mechanism is not clear. In this study, Sal B significantly decreased fasting blood glucose and lipid levels, and improved insulin sensitivity in $d b / d b$ mice with similar effectiveness as metformin, which were consistent with our previous reports of Sal B in type 2 diabetic rats and dietinduced obese mice [17-19]. Sal B also ameliorated the histopathological alterations of pancreas. Most importantly, it demonstrated that Sal B effectively influences AMPK pathway in both skeletal muscle and liver, and within these tissue types Sal B induces a variety of beneficial metabolic effects. These include increased glycolysis gene expressions (PK, GK); and decreased gluconeogenesis gene expressions (G6Pase, PEPCK); increased muscle glycogen content; increased protein expressions of GLUT4 and glycogen synthase in skeletal muscle; increased p-AMPK protein expression in skeletal muscle and liver; increased protein expressions of PPAR $\alpha$ and p-ACC in liver.

The intracellular AMPK signaling cascade is a cellular energy status sensor. Activation of AMPK is known to down-regulate several biosynthetic pathways, such as gluconeogenesis and fatty acid synthesis in the liver, and to switch on several catabolic pathways for ATP generation such as glucose uptake (up-regulation of GLUT-4) and glycolysis [24, 25]. Activation of AMPK triggers intracellular metabolic changes that would be beneficial in 
Fig. 5. Effects of Sal B on p-AMPK, AMPK, PPAR $\alpha$, and p-ACC protein expression in liver of $\mathrm{C} 57 \mathrm{BL} / \mathrm{Ks}$ $d b / d b$ mice. A: equal amounts of proteins were resolved on $10 \%$ SDS-PAGE and blotted with respective p-AMPK, AMPK, PPAR $\alpha$, and p-ACC antibodies. B-E: the densitometric measurements of protein bands in A. Data are expressed as mean \pm SEM $(n=5)$. ${ }^{a b c}$ Means not sharing common superscript letters are significantly different between groups at $p<$ 0.05 .

\section{A}

Liver

Con Sal B-50 Sal B-100 Met

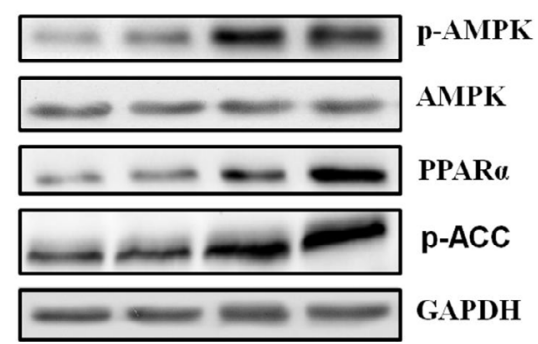

B

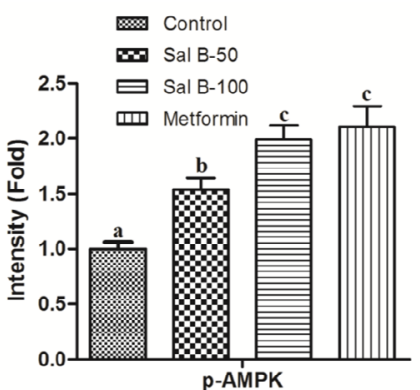

C

D

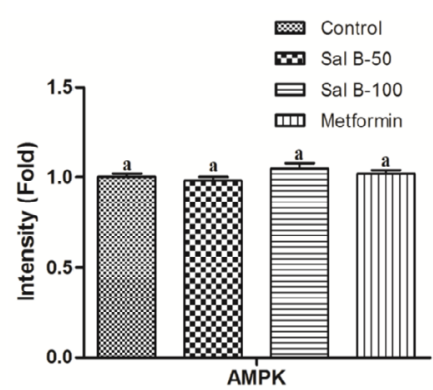

$$
\text { E }
$$
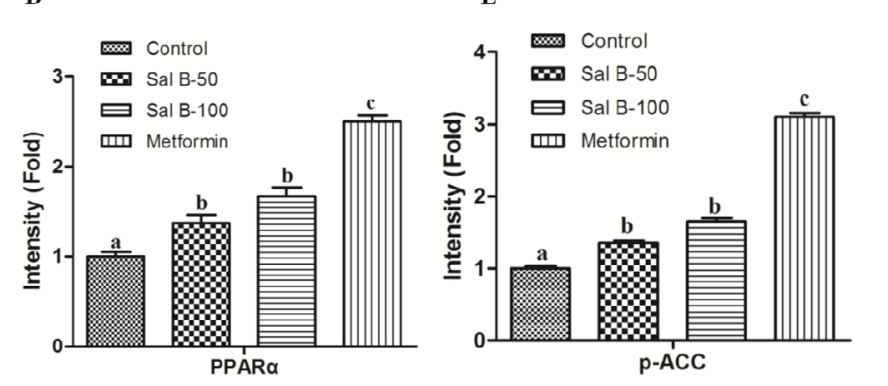

Fig. 6. Effect of SalB on pancreatic morphological changes in C57BL/KsJ-db/ $d b$ mice $(\mathrm{n}=5)$. A: control $d b / d b$ mice group. B: low-dose Sal B treated group. C: high-dose Sal B treated group. D: metformin treated group. Original magnification $200 \times$.

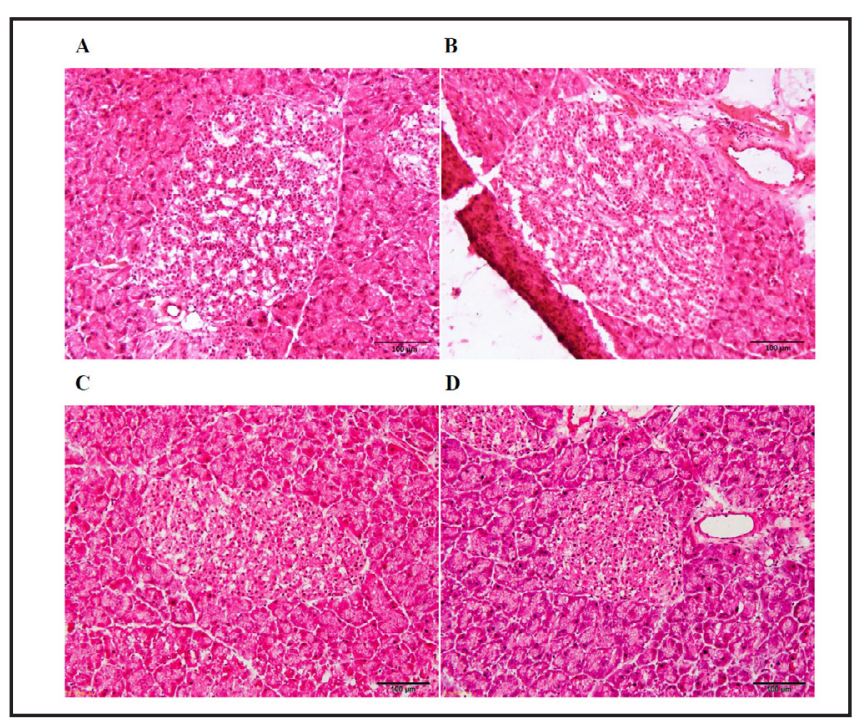

diabetic patients, such as increased glucose uptake in muscles and other tissues, decreased glucose production in liver, and decreased fatty acid synthesis and increased fatty acid oxidation [24, 25]. In the present study, Sal B at two doses (50 and $100 \mathrm{mg} / \mathrm{kg}$ ) significantly 


\section{Cellular Physiology Cell Physiol Biochem 2016;40:933-943

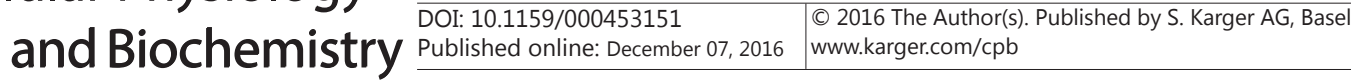 \\ Huang et al.: Salvianolic Acid B Ameliorates Hyperglycemia and Dyslipidemia}

increased phosphorylation of AMPK in both skeletal muscle and liver, without affecting total AMPK level. Furthermore, it shown that several AMPK downstream effectors are regulated by Sal B treatment in $d b / d b$ mice.

It was reported that activation of AMPK stimulate glucose uptake by enhancing translocation of GLUT4 to the plasma membrane in skeletal muscle [32]. Insulin resistance in skeletal muscle is supposed to related with reduced GLUT4 translocation and glycogen synthesis in type 2 diabetes [33]. In the current study, different doses of Sal B all increased GLUT4 protein expression in skeletal muscle of $d b / d b$ mice, suggesting that Sal B can stimulate glucose uptake via enhancing GLUT4 translocation. The effect of Sal B on GLUT4 is consistent with the decrease in fasting blood glucose and the improvement in glucose tolerance and insulin tolerance in Sal B treated diabetic mice. As one of rate-limiting enzymes in glycogen synthesis, glycogen synthase is also a downstream target of AMPK [21]. Our results shown that glycogen synthase protein expression in skeletal muscle was enhanced by Sal B compared to the control mice. Consistent with the up-regulation of glycogen synthase, Sal B $(100 \mathrm{mg} / \mathrm{kg})$ led to a significant increase in muscle glycogen content in $d b / d b$ mice.

In liver, elevated hepatic glucose production is a major contributor to hyperglycemia in type 2 diabetes [34]. AMPK activation inhibits hepatic glucose production by lowering expression of gluconeogenic enzymes (PEPCK, G6Pase), and stimulates glycolysis by enhancing expressions of glycolytic enzyme (GK, PK) [34]. In this study, hepatic PEPCK and G6Pase mRNA expressions were significantly decreased in Sal B (100 mg/kg) treated $d b / d b$ mice. In contrast, hepatic GK and PK mRNA expressions were significantly increased in high dose of Sal B treated $d b / d b$ mice. Taken together, these results indicate that Sal B inhibits gluconeogenic enzyme gene expression and enhances glycolytic enzyme gene expression, hence may help explain that Sal B induced improvements in glycemic control.

AMPK also plays a important role in lipid metabolism regulation via action on downstream targets. AMPK-regulated ACC inhibition reduces malonyl CoA content and subsequently leads to reduced fatty acids synthesis and increased mitochondrial fatty acid oxidation [25,34]. In the current study, phosphorylation of ACC was significantly increased by Sal B treatment in liver. Moreover, PPAR $\alpha$, a important transcription factor regulating lipid metabolism genes, is reported to be one of important downstream targets of AMPK [24]. Herein, PPAR $\alpha$ protein expression in liver was markedly elevated by Sal B treatment. In parallel with above these protein changes, serum levels of TC, TG, and FFA were also markedly decreased in Sal B treated $d b / d b$ mice. Taken together, these findings suggest Sal $B$ alleviates dyslipidemic state partly by regulation of the AMPK downstream effectors such as ACC and PPAR $\alpha$.

In conclusion, we present evidence that Sal B exerts beneficial effects on hyperglycemia, dyslipidemia, glucose intolerance, and insulin intolerance as well as protecting against pancreatic histopathological alterations in $d b / d b$ mice, which naturally develop type 2 diabetes. The present results suggest that the mechanism of Sal B at least in part involves modulation of the AMPK pathway. These findings indicate that Sal B is a potential agent for the prevention and treatment of type 2 diabetes.

\section{Acknowledgment}

The work was supported by the National Natural Science Foundation of China (81373940, 81503204, 81673561), the Program for New Century Excellent Talents in Fujian Province University ([2015]54) and the Shenzhen Key Laboratory Program (ZDSYS201506050935272).

\section{Disclosure Statement}

None.

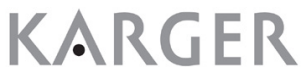




\section{Cellular Physiology Cell Physiol Biochem 2016;40:933-943

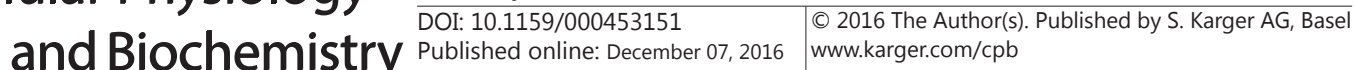 \\ Huang et al.: Salvianolic Acid B Ameliorates Hyperglycemia and Dyslipidemia}

\section{References}

1 Tahrani AA, Piya MK, Kennedy A, Barnett AH: Glycaemic control in type 2 diabetes: Targets and new therapies. Pharmacol Ther 2010;125:328-361.

2 Nolan CJ, Ruderman NB, Kahn SE, Pedersen O, Prentki M: Insulin resistance as a physiological defense against metabolic stress: Implications for the management of subsets of type 2 diabetes. Diabetes 2015;64:673-686.

3 Shaw JE, Sicree RA, Zimmet PZ: Global estimates of the prevalence of diabetes for 2010 and 2030. Diabetes Res Clin Pract 2010;87:4-14.

4 Yang W, Lu J, Weng J, Jia W, Ji L, Xiao J, Shan Z, Liu J, Tian H, Ji Q, Zhu D, Ge J, Lin L, Chen L, Guo X, Zhao Z, Li Q, Zhou Z, Shan G, He J: Prevalence of diabetes among men and women in china. N Engl J Med 2010;362:1090-1101.

5 Tahrani AA, Barnett AH, Bailey CJ: Pharmacology and therapeutic implications of current drugs for type 2 diabetes mellitus. Nat Rev Endocrinol 2016;12:566-592.

6 Prabhakar PK, Doble M: A target based therapeutic approach towards diabetes mellitus using medicinal plants. Curr Diabetes Rev 2008;4:291-308.

7 Xu X, Liang T, Lin X, Wen Q Liang X, Li W, Qin F, Zheng N, Ming J, Huang R: Effect of the total extract of averrhoacarambola (oxalidaceae) root on the expression levels of tlr4 and nf-kappab in streptozotocininduced diabetic mice. Cell Physiol Biochem 2015;36:2307-2316.

8 Jiang RW, Lau KM, Hon PM, Mak TC, Woo KS, Fung KP: Chemistry and biological activities of caffeic acid derivatives from salvia miltiorrhiza. Curr Med Chem 2005;12:237-246.

9 Zhou L, Zuo Z, Chow MS: Danshen: An overview of its chemistry, pharmacology, pharmacokinetics, and clinical use. J Clin Pharmacol 2005;45:1345-1359.

10 Lei XL, Chiou GC: Studies on cardiovascular actions of salvia miltiorrhiza. Am J Chin Med 1986;14:26-32.

11 Qiang G, Yang X, Shi L, Zhang H, Chen B, Zhao Y, Zu M, Zhou D, Guo J, Yang H, Zhang L, Du G: Antidiabetic effect of salvianolic acid a on diabetic animal models via ampk activation and mitochondrial regulation. Cell Physiol Biochem 2015;36:395-408.

12 Xie P, Duan Y, Guo X, Hu L, Yu M: Sala attenuates hypoxia-induced endothelial endoplasmic reticulum stress and apoptosis via down-regulation of vldl receptor expression. Cell Physiol Biochem 2015;35:17-28.

13 Yang D, Zhang P, Wang T, Gao L, Qiao Z, Liang Y, Yu B: Sala attenuates ischemia/reperfusion-induced endothelial barrier dysfunction via down-regulation of vldl receptor expression. Cell Physiol Biochem 2014;33:747-757.

14 Cao W, Guo XW, Zheng HZ, Li DP, Jia GB, Wang J: Current progress of research on pharmacologic actions of salvianolic acid b. Chin J Integr Med 2012;18:316-320.

15 Lin C, Liu Z, Lu Y, Yao Y, Zhang Y, Ma Z, Kuai M, Sun X, Sun S, Jing Y, Yu L, Li Y, Zhang Q Bian H: Cardioprotective effect of salvianolic acid $\mathrm{b}$ on acute myocardial infarction by promoting autophagy and neovascularization and inhibiting apoptosis. J Pharm Pharmacol 2016;68:941-952.

16 Lv H, Wang L, Shen J, Hao S, Ming A, Wang X, Su F, Zhang Z: Salvianolic acid b attenuates apoptosis and inflammation via sirt1 activation in experimental stroke rats. Brain Res Bull 2015;115:30-36.

17 Huang M, Xie Y, Chen L, Chu K, Wu S, Lu J, Chen X, Wang Y, Lai X: Antidiabetic effect of the total polyphenolic acids fraction from salvia miltiorrhiza bunge in diabetic rats. Phytother Res 2012;26:944-948.

18 Wang P, Xu S, Li W, Wang F, Yang Z, Jiang L, Wang Q, Huang M, Zhou P: Salvianolic acid b inhibited ppargamma expression and attenuated weight gain in mice with high-fat diet-induced obesity. Cell Physiol Biochem 2014;34:288-298.

19 Huang M, Wang P, Xu S, Xu W, Chu K, Lu J: Biological activities of salvianolic acid b from salvia miltiorrhiza on type 2 diabetes induced by high-fat diet and streptozotocin. Pharm Biol 2015;53:1058-1065.

20 Raoufi S, Baluchnejadmojarad T, Roghani M, Ghazanfari T, Khojasteh F, Mansouri M: Antidiabetic potential of salvianolic acid b in multiple low-dose streptozotocin-induced diabetes. Pharm Biol 2015;53:1803-1809.

21 Hsu FL, Huang CF, Chen YW, Yen YP, Wu CT, Uang BJ, Yang RS, Liu SH: Antidiabetic effects of pterosin a, a small-molecular-weight natural product, on diabetic mouse models. Diabetes 2013;62:628-638.

22 King AJ: The use of animal models in diabetes research. Br J Pharmacol 2012;166:877-894.

23 Do GM, Jung UJ, Park HJ, Kwon EY, Jeon SM, McGregor RA, Choi MS: Resveratrol ameliorates diabetesrelated metabolic changes via activation of amp-activated protein kinase and its downstream targets in $\mathrm{db} /$ db mice. Mol Nutr Food Res 2012;56:1282-1291. 


\section{Cellular Physiology Cell Physiol Biochem 2016;40:933-943 \begin{tabular}{ll|l} 
DOI: 10.1159/000453151 & $\begin{array}{l}\text { O 2016 The Author(s). Published by S. Karger AG, Basel } \\
\text { www.karger.com/cpb }\end{array}$
\end{tabular} \\ Huang et al.: Salvianolic Acid B Ameliorates Hyperglycemia and Dyslipidemia}

24 Hardie DG: The amp-activated protein kinase pathway--new players upstream and downstream. J Cell Sci 2004;117:5479-5487.

25 Hardie DG: Minireview: The amp-activated protein kinase cascade: The key sensor of cellular energy status. Endocrinology 2003;144:5179-5183.

26 Fryer LG, Parbu-Patel A, Carling D: The anti-diabetic drugs rosiglitazone and metformin stimulate ampactivated protein kinase through distinct signaling pathways. J Biol Chem 2002;277:25226-25232.

27 Xu M, Xiao Y, Yin J, Hou W, Yu X, Shen L, Liu F, Wei L, Jia W: Berberine promotes glucose consumption independently of amp-activated protein kinase activation. PLoS One 2014;9:e103702.

28 Lakshmanan AP, Watanabe K, Thandavarayan RA, Sari FR, Meilei H, Soetikno V, Arumugam S, Giridharan VV, Suzuki K, Kodama M: Curcumin attenuates hyperglycaemia-mediated ampk activation and oxidative stress in cerebrum of streptozotocin-induced diabetic rat. Free Radic Res 2011;45:788-795.

29 Keller AC, Ma J, Kavalier A, He K, Brillantes AM, Kennelly EJ: Saponins from the traditional medicinal plant momordica charantia stimulate insulin secretion in vitro. Phytomedicine 2011;19:32-37.

30 Lee YS, Kim WS, Kim KH, Yoon MJ, Cho HJ, Shen Y, Ye JM, Lee CH, Oh WK, Kim CT, Hohnen-Behrens C, Gosby A, Kraegen EW, James DE, Kim JB: Berberine, a natural plant product, activates amp-activated protein kinase with beneficial metabolic effects in diabetic and insulin-resistant states. Diabetes 2006;55:22562264.

31 Lee SH, Ko SC, Kang MC, Lee DH, Jeon YJ: Octaphlorethol a, a marine algae product, exhibits antidiabetic effects in type 2 diabetic mice by activating amp-activated protein kinase and upregulating the expression of glucose transporter 4. Food Chem Toxicol 2016;91:58-64.

32 Kim J, Yang G, Kim Y, Ha J: Ampk activators: Mechanisms of action and physiological activities. Exp Mol Med 2016;48:e224.

33 Cline GW, Petersen KF, Krssak M, Shen J, Hundal RS, Trajanoski Z, Inzucchi S, Dresner A, Rothman DL, Shulman GI: Impaired glucose transport as a cause of decreased insulin-stimulated muscle glycogen synthesis in type 2 diabetes. N Engl J Med 1999;341:240-246.

34 Coughlan KA, Valentine RJ, Ruderman NB, Saha AK: Ampk activation: A therapeutic target for type 2 diabetes? Diabetes Metab Syndr Obes 2014;7:241-253. 